\title{
NOTAS SOBRE JUSTICIA CONSTITUCIONAL E INTERPRETACIÓN DE LA CONSTITUCIÓN (O EN DEFENSA DE LA INTERPRETACIÓN COMO DIÁlOGO)
}

\author{
MIGUEL REVENGA SÁNCHEZ \\ Catedrático de Derecho Constitucional \\ Universidad de Carlos III
}

Pocas afirmaciones despiertan entre nosotros un acuerdo tan generalizado como la que se refiere a la interpretación de la Constitución como el problema, por antonomasia de la teoría y el Derecho Constitucional de nuestros días. En Europa y, desde luego, en España, el Derecho Constitucional no hace mucho tiempo que disfruta de las ventajas que, para la dignidad científica de dicha rama del Derecho como disciplina académica, se derivan de la judicialización de sus enunciados. Pero, una vez descubierta la terra ignota del laboratorio judicial, una vez sobrepasadas las horas que alguien llamó "de pavorosa soledad" de los cultivadores de un Derecho que, por marcar distancias con el pasado, cambió hasta el nombre, parece como si, más allá del juicio de constitucionalidad, no hubiera sino el vacío ${ }^{1}$.

El "entusiasmo" por la judicialización es comprensible, pero a veces induce a sostener tesis, desde mi punto de vista, erróneas. Por ejemplo, no creo que el

1 Lo de las "horas de pavorosa soledad" está tomado de una recensión de Lorenzo Martín Retortillo, publicada en 1981, que contiene un irónico alegato contra el oportunismo que, creía él, se avecinaba: «hace Derecho Constitucional quien hace Derecho Constitucional, siempre que haga Derecho Constitucional. Lo malo sería confundir la ciencia con la longaniza y alardear de científico con la mira puesta, en cambio, en el banquete. Porque, al igual que en los bodegones barrocos se acumulan y arraciman frutos y más frutos y aun piezas de caza, hoy en el ámbito del Derecho Constitucional se ofrece, atractivo y sugeridor, un panorama, auténtica tierra de promisión, henchido de incienso y oro — tal vez sólo de plata — con el sueño de la lluvia de asuntos, de pleitos — ya hay un Tribunal Constitucional funcionando- y de dictámenes (...). Porque el hacer ciencia está, y ha estado abierto, a todos; todos los que quisieron pudieron empujar en esta a veces lenta, tan desasistida, tan desvencijada, en ocasiones, carreta de la ciencia del Derecho Constitucional, que conoció horas de pavorosa soledad.. El libro recensionado era el Derecho Presupuestario, de Laband, en la edición al cuidado, y con un excelente estudio introductorio, de Álvaro RODRÍGUEZ BEREIJ; cfr. Revista de Administración Pública, 96 (1981), pp. 439 y ss. 
ámbito objetivo del Derecho Constitucional pueda delimitarse, como a veces se hace, mediante la exclusiva referencia a los mandatos constitucionales y a la interpretación de los mismos verificada por la jurisprudencia constitucional. Se trata de un empeño que suele inscribirse dentro del contexto de un discurso sobre las fuentes de nuestra disciplina, y donde el "pie forzado" del enfoque (la tesis formalista/tradicional de las fuentes, con la jurisprudencia como fuente auxiliar) obliga a marcar distancias, removiendo las aguas, más estancadas que turbulentas, de la hidráulica jurídica.

Bromas aparte, hoy no son pocos los autores que denuncian la «hiper-formalización" producida en nuestro pujante Derecho Constitucional como consecuencia de una "estrategia de exclusiones", que tendía a deslegitimar cualquier enfoque no apegado a la cita jurisprudencial. Transcurridos ya los tiempos en los que todo estaba por hacer en materia ordinamental (fuentes, cauces de garantía, relaciones entre los subsistemas estatal y autonómico, etc.), y superada la proclividad al anatema, quizá estamos asistiendo a un movimiento pendular que reclama de los especialistas una mayor dedicación al trasfondo político de las normas, y al engarce de éstas con la realidad ${ }^{2}$.

La fascinación por la justicia constitucional induce también a cierta desmesura cuando, hablando en términos generales, se hace de ella una exigencia ineluctable para la salvaguarda de la supremacía constitucional y aun de la propia democracia. Se olvida así que la jurisdicción constitucional fue un expediente introducido en Europa en circunstancias bien concretas, las de unas democracias amenazadas, y en las que la defensa de la Constitución se planteó como un problema acuciante. Podría así decirse que en Europa la quiebra de la democracia ha actuado históricamente como un acicate para la incorporación y difusión de la justicia constitucional ${ }^{3}$. Mientras que, a la inversa, la ausencia de ésta en sistemas democráticos bien consolidados, no es un rasgo deficitario de los mismos, sino sencillamente indicio de una evolución hacia la democracia carente de sobresaltos.

2 En este sentido, he leído últimamente dos opiniones muy autorizadas, la de Luis López Guerra, en su Proyecto para el acceso a una cátedra en la Universidad Carlos III ("la tarea que se muestra en estos momentos más necesitada de atención de los especialistas del Derecho Constitucional es el análisis, exposición y clarificación de cuáles sean los contenidos materiales de las normas constitucionales, en relación con su significado político, en cuanto opciones concretas entre diversas alternativas presentes", y la de Oscar Alzaga en la "Razón de ser", escrita a modo de exordio del n. ${ }^{\circ} 1$ de esta revista, de expresivo título, Teoría y Realidad constitucional ("Creemos poco fructíferos los enfoques evasivos, por mucho que se cubran con ropajes aparentemente ricos y brillantes, y entendemos que hasta el profesor más seducido por la estética y el sex appeal del formalismo acabará encontrando fascinante el difícil mundo de las relaciones entre la Constitución, en concreto, y las normas políticas, en general, con la realidad. Nuestro sentido del olfato, vieja y fiable fuente de conocimientos, nos dice que de la conexión entre teoría y realidad podemos esperar un nuevo y fuerte impulso de nuestra Ciencia").

3 Cfr. Francisco RUBIO LLORENTE, "Seis tesis sobre la jurisdicción constitucional en Europa", Revista Española de Derecho Constitucional, 35 (1992), pp. 9 y ss.; más recientemente, abunda en la misma idea Luis López Guerra en su "Introducción" a la selección jurisprudencial llevada a cabo por él, bajo el título Las sentencias básicas del Tribunal Constitucional, Madrid, BOE/CEPC, 1998. 
En los últimos tiempos, el debate filosófico-político registra también algunas objeciones frente a la importancia cobrada por la justicia constitucional. Una muestra significativa es el influyente libro de Habermas, Faktizität und Geltung, cuyo Capítulo 6 versa sobre las relaciones entre la jurisdicción y la legislación y, más precisamente, sobre la "función y legitimidad de la jurisprudencia constitucional». Habermas parte de las ideas de Dworkin relativas a los derechos y la decisión judicial, que examina en el Capítulo 5 ("Indeterminación del Derecho y racionalidad de la jurisdicción"), confrontándolas con la posición de autores alemanes (Denninger, Maus y Böckenförde, sobre todo) y norteamericanos (Sunstein, Perry, Brest, Ackerman y Ely, entre otros). Si he comprendido bien el punto de vista de Habermas, éste resalta los riesgos que, para la certeza del derecho, se derivan del excesivo peso de una jurisprudencia "creadora" y dimanante de un Tribunal que tiende a ocupar el puesto reservado, según la lógica de la división de poderes, al legislador democrático ${ }^{4}$. Habermas simpatiza con las tesis preconizadas por Ely, contrarias al "paternalismo" del Tribunal Supremo, y defensoras de una función de éste meramente garantista/procedimental:

"El discurso jurídico — dice Habermas- puede disfrutar de una presunción de racionalidad relativamente alta, debido a que está especializado en cuestiones concernientes a la aplicación de las normas, y se beneficia además de una forma de institucionalización que resalta su condición de tercero imparcial entre las partes en causa. Pero precisamente por ello el discurso jurídico no puede sustituir al discurso político, que es el que tiene que aportar su razón de ser a las normas y a los programas de acción, previo un debate en el que tengan oportunidad de intervenir todas las partes interesadas, 5 .

Consecuente con esa reivindicación de lo político, Habermas se apoya en construcciones del alemán Denninger y del norteamericano Sunstein, para calificar como la más importante de las funciones de la justicia constitucional la de actuar como un guardián de la democracia deliberativa ${ }^{6}$. Del primer autor citado toma la idea de los "conceptos-clave del Derecho Constitucional", es decir aquellos de los que se sirve habitualmente la jurisdicción constitucional, y que se corresponden con las transformaciones experimentadas por los derechos fundamentales en el Estado democrático: desde su condición de derechos subjetivos o de defensa frente al Estado, a su estatuto como principios objetivos del ordenamiento con proyección sobre el con-

4 Cito por la edición italiana: Jürgen HABERMAS, Fatti e Norme. Contributi a una teoria discorsiva del diritto e della democrazia, Milán, Guerini, 1996, p. 301.

5 Fatti e norme..., p. 316. Abunda en ideas semejantes el libro de Mark Tushnet, de expresivo titulo, Taking the Constitution away from the Courts, Princeton, Princeton University Press, 1999.

6 Categoría, como es sabido, central en el pensamiento de Habermas. En español, pueden verse sus escritos agrupados bajo el epígrafe "QQué significa política deliberativa?", en Habermas, $L a$ inclusión del otro. Estudios de teoría política, Barcelona, Paidós, 1999, así como la excelente visión de conjunto sobre el pensamiento habermasiano de Fernando VALLESPÍN, "Habermas en doce mil palabras", Claves de razón práctica, 114 (2001), pp. 53 y ss. 
junto de éste ${ }^{7}$. Tales conceptos-clave, utilizados rutinariamente por la jurisdicción constitucional son, entre otros, el principio de proporcionalidad, el de razonabilidad, la recíproca limitación de los derechos y el juicio de ponderación, la unidad de la Constitución, etc. ${ }^{8}$.

De Sunstein, por su parte, toma Habermas una categoría próxima a la de los conceptos-clave, llamada por el autor norteamericano background norms. Se trata de una serie de principios inspiradores, que son propugnados como guía de conducta o, más bien, cánones de autocontención, que los Tribunales deberían seguir, con el fin de lograr el mayor consenso posible en materia de interpretación jurídica (y no sólo constitucional). Con tal propósito se enuncian una serie de postulados que ahora no voy a reproducir, pero que, en sustancia, se inspiran en el común objetivo de lograr que el debate político no salga de los cauces en los que debería desarrollarse y, subsidiariamente, en el de sugerir argumentos para el debate, garantizando, eso sí, una sustancial igualdad de oportunidades políticas para la defensa de las diferentes perspectivas $^{9}$.

Con posterioridad a la aparición del libro de Habermas, el propio Sunstein ha expuesto su pensamiento al respecto, de manera más profunda y sistemática, en su brillante ensayo sobre las relaciones entre conflicto político y razonamiento jurídico ${ }^{10}$. La tesis básica del libro es que un sistema jurídico que funcione de modo mínimamente satisfactorio debe tener como objetivo generar estabilidad y consenso, en el contexto de elevadas dosis de desacuerdo político y pluralismo. A tal efecto, los Tribunales - y sobre todo aquellos con capacidad decisoria de carácter último— deben, al decir de Sunstein, operar por medio de lo que él llama (algo así como) «acuerdos teóricos no desarrollados exhaustivamente" (Incompletely Theorized Arguments). Tales argumentos permiten razonar desde un nivel de abstracción lo suficientemente elevado como para suscitar un acuerdo generalizado sobre las posiciones de principio, que podría romperse si la lógica argumentativa descendiera hasta las minucias de detalle del caso concreto. En diversos lugares de su libro, Sunstein insiste, por ello, en lo eficaz que resulta un "uso constructivo del silencio" por parte de los

7 Sobre esto, véase también el trabajo de Peter HÄBERLE, "Recientes desarrollos sobre derechos fundamentales en Alemania", pp. 149 y ss.

8 Erhard DENNINGER, "Verfassungsrechtliche Schlüselbegiffe", en Der gebändigte Leviathan, Baden-Baden, 1990; cfr. Habermas, Fatti e norme..., pp. 292 y ss. De entre la abundantísima bibliografía dedicada al análisis de tales conceptos, cabe destacar el excelente número monográfico (el 5, de 1998), que dedicó al principio de proporcionalidad la revista Cuadernos de Derecho Público; también, por lo que se refiere a la ponderación, la monografía (de engañoso título) de José María Rodríguez Santiago, La ponderación de bienes e intereses en el Derecho Administrativo, Madrid, Marcial Pons, 2000. Y sobre el juicio de razonabilidad, Gino SCACCIA, Gli "strumenti" della ragionevolezza nel giudizio costituzionale, Milán, Giuffrè, 2000.

9 C.R. SUNSTEIN, After the Rights Revolution, Cambridge, 1990, pp. 170 y ss.; cfr. Habermas, Fatti e norme, cit., pp. 299-301, y 328-329.

10 C. R. SUNSTEIN, Legal Reasoning and Political Conflict, Nueva York, Oxford University Press, 1996. 
Tribunales, así como en el valor del razonamiento analógico para la resolución de los casos de Derecho Constitucional ${ }^{11}$.

Si se acepta la idea, por otra parte bien difícil de rechazar, de que un derecho por principios conlleva elevadas dosis de creación en el momento de ser interpretado, entonces lo que los autores citados (y con ellos Habermas) dicen es simplemente que el responsable de la interpretación necesita una justificación externa. Ahora bien, decidir cuál sea esa justificación y enunciar, sobre la base de ella, unos determinados modelos de comportamiento, ya es cosa que entra en el terreno de la prescripción, por más que el pretexto de la misma sea uno de tanto fuste como la defensa del legislador democrático. En una dirección semejante, también Rawls otorga a la justicia constitucional nada menos que el estatuto de paradigma de la razón públi$c a$ ("en un régimen constitucional con revisión judicial de la constitucionalidad de las leyes, la razón pública no es otra cosa que la razón de su Tribunal Supremo"), pero en un contexto de vigorosa defensa de la separación de poderes:

"La Constitución —añade Rawls algunas páginas más adelante- no es lo que el Tribunal dice que es, sino aquello que, sobre ella, le permiten decir quienes actúan de conformidad con la Constitución en las otras ramas del Gobierno" ${ }^{12}$

Bien están los wishful thinkings, estemos o no de acuerdo con ellos, pero lo cierto es que las dimensiones cobradas por la justicia constitucional otorgan al constitucionalismo de nuestros días un sesgo por completo inédito. La imagen kelseniana del legislador negativo resulta inadecuada para dar cuenta de una realidad en la que la jurisprudencia constitucional se ha convertido en fuente positiva de criterios interpretativos de alcance general y vinculante (artículo 5 LOPJ, por lo que se refiere a España). Lo que ha cambiado, quizá, no es tanto la función de la justicia constitucional, que continúa siendo, como en el debate clásico, defensiva de la Constitución, como la manera (por así decir rutinaria) en que tal defensa se realiza, así como la transformación de lo que la misma exige.

Por decirlo más claramente: mientras que la imagen clásica del legislador negativo tiene como presupuesto la defensa de la norma fundamental frente a la ley, mediante un juicio abstracto de compatibilidad entre ambas normas cerradas, la visón contemporánea de la justicia constitucional presupone una Constitución abierta, unos enunciados que no se prestan a formas silogísticas

11 Legal Reasoning... Capítulos II ("Incompletely Theorized Arguments") y III ("Analogical Reasoning"). El recurso a los I.T.A., en el momento de la elaboración de la Constitución, viene desarrollado por el propio Sunstein en su trabajo "Constitutional Agreement Without Constitutional Theories", Ratio Iuris, 13 (2000), pp. 117 y ss. Sobre el uso de la analogía en Derecho Constitucional, cfr. también la obra de Victor FERRERES COMELLA, Justicia Constitucional y Democracia, Madrid, Centro de Estudios Constitucionales, 1997.

12 J. RAWLS, Political Liberalism, Nueva York, Columbia University Press, 1993, pp. 231 y 237 y, en general, Lecture VI ("The Idea of Public Reason"). 
de enjuiciamiento, y un orden constitucional que se va creando y recreando mediante la actuación conforme a aquélla de los ciudadanos y de los poderes públicos, incluido el Tribunal Constitucional.

Las tensiones entre el legislador y la jurisdicción constitucional se convierten así en un componente inevitable de nuestras democracias, un fenómeno inherente a las mismas y frente al cual, como se ha dicho, la marcha atrás parece imposible ${ }^{13}$. Con el fin de mantener dicha tensión dentro de márgenes que no hagan de ella un mal endémico o una rémora insostenible para el funcionamiento del sistema — cosa que, por el momento, no se ve que esté en trance de ocurrir en ningún lado, pese a las protestas y denuncias de usurpación llevadas a cabo por algunos destacados originalistas norteamericanos ${ }^{14}$ - se han sugerido medidas "de ingeniería constitucional" dirigidas a instaurar mecanismos de cooperación entre las dos instituciones. Presupuesto para la adopción de las mismas, es "abandonar viejos tabúes por ambas partes, como la crítica per se a las sentencias que contienen orientaciones para el legislador, o la creencia de los Tribunales Constitucionales de que la inercia (pereza) del legislador es algo consustancial a las Cámaras" "15.

Y desde un plano más teórico, esta especie de "Constitución de los controladores", que hoy tenemos, puede ser contemplada desde perspectivas opuestas: bien como una regresión antidemocrática, en el sentido de que esconde la politicidad radical de decisiones colectivas básicas bajo el manto de un tecnicismo constitucional cuyos entresijos sólo unos pocos están en disposición de conocer, o bien como el perfeccionamiento y culminación de la aspiración garantizadora/limitadora que siempre alumbró al constitucionalismo ${ }^{16}$.

De lo que no cabe duda es que el panorama "dieciochesco" de frenos y contrapesos, de cuyo correcto engranaje en la maquinaria constitucional se esperaba todo para la salvaguarda de la libertad, se ha hecho más complejo. Para unos, la virtud del Poder Judicial, en un contexto en que todo y todos somos justiciables, se ha convertido en la depositaria natural de tal esperan-

13 Cfr. las "Conclusiones generales", a cargo de Eliseo AJA y Markus GONZÁLEZ BEILFUSS, a la obra colectiva, coordinada por el primero, Las tensiones entre el Tribunal Constitucional y el Legislador en la Europa actual, Barcelona, Ariel, 1998.

14 Me refiero, sobre todo, a Robert BORK y a su irritada obra, The Tempting of America. The Political Seduction of the Law, Nueva York, Simon and Shuster, 1990, especialmente Cpt.18 («Effects for the Future").

15 AJA y GONZÁLEZ, "Conclusiones Generales", cit. Con referencia a Italia, pueden verse consideraciones semejantes en el libro de Enzo CHELI, Il Giudice delle leggi. La Corte Costituzionale nella dinamica dei poteri, Bolonia, Il Mulino, 1996, pp. 64 y ss.

16 Claramente decantado por el primer polo de la alternativa se muestra TUSHNET, Taking the Constitution away from the Courts, Princeton, Princeton University Press, 1999, mientras que un representante señero de la segunda opción es Bruce Ackerman, cuya teoría constitucional de la democracia dualista, con los "momentos constitucionales" y los de la "política normal", va acompañada de la reivindicación entusiasta del juicio de constitucionalidad, que aparece en escena para cumplir la promesa de lo político, no para acabar con ellan; cfr, en general, sus ensayos agrupados bajo el título La política del diálogo liberal, Barcelona, Gedisa, 1999 y, especialmente, el titulado “El argumento político a favor de los tribunales constitucionales" (pp. 145 y ss.). 
$\mathrm{za}^{17}$. Otros reproducen la "obsesión trinitaria", y explican el nuevo estado de cosas hablando de un equilibrio inestable y polimorfo entre tres polos: el de la tecno-burocracia, el de las instituciones democrático-representativas y el del Estado ético de los controladores ${ }^{18}$. Y otros, en fin, con acusado optimismo, recurren a la imagen de la "sociedad abierta de los intérpretes constitucionales", sin numerus clausus de ellos, en claro decantamiento, entre las alternativas antes enunciadas, favorable al reforzamiento del constitucionalismo ${ }^{19}$.

La popperiana búsqueda de la verdad, a través de un proceso racional y discursivo, con resultados siempre aproximativos y provisionales, se ha convertido en un tópico por el que la ciencia del Derecho Constitucional muestra cada vez más interés ${ }^{20}$. Quizá a ella, como al Derecho en general, siempre que éste sea concebido como público intercambio de razones, sostenido por un consenso social, y dirigido al logro de una convivencia pacífica, le cuadra al dedillo la bella imagen de la tela tejida de conjeturas. Con ella concluía el filósofo griego Jenófanes, 500 años antes de Cristo, unos versos dirigidos a demostrar que aquello que denominamos conocimiento no es sino conjetura y opinión, doxa, no episteme:

"Los dioses no nos revelaron, desde el principio, todas las cosas a los humanos; pero en el curso del tiempo,podemos aprender indagando, y conocer mejor las cosas. Por lo que respecta a la verdad certera, nadie la conoce, ni la conocerá; ni acerca de los dioses, ni tampoco de todas las cosas de las que hablo. E incluso si por azar alguien llegase a expresar la verdad perfecta, lo desconocería: pues todo no es más que una tela tejida de conjeturas" ${ }^{21}$.

17 Cfr. Michel TROPER, Pour une Théorie juridique de l'État, Paris, P.U.F, 1994, especialmente Cpt. XIII ("Le concept de constitutionalisme et la théorie moderne du droit"). La expresión todo y todos somos justiciables es de A. Garapon, Le gardien des promesses, París, Odile JACOB, 1996, p. 21; para la cuestión, es muy útil el trabajo de Guarnieri y Pederzoli La democrazia giudiziaria, Bolonia, Il Mulino, 1997.

18 Cfr. Pier Paolo PORTINARO, "Dal custode della Costituzione alla Costituzione dei custodi", en Gustavo GOZZI (ed.), Democrazia, diritti, costituzione. I fondamenti costituzionali delle democrazie contemporanee, Bolonia, Il Mulino, 1997, pp. 401 y ss.

19 La referencia canónica es, naturalmente, HÄBERLE, "La sociedad abierta de los intérpretes constitucionales. Una contribución para la interpretación pluralista y 'procesal' de la Constitución", en Retos actuales del Estado constitucional, Oñati, IVAP, 1996, pp. 15 y ss., especialmente p. 31: "Limitar la interpretación constitucional a los intérpretes estatales 'gremiales', acreditados funcional-jurídicamente, sería empobrecimiento o autoengaño. Especialmente una concepción más experimental de la ciencia del Derecho constitucional como ciencia normativa y de la realidad no puede renunciar a la fantasía y fuerza creadora de los intérpretes 'no gremiales' en el proceso de la interpretación constitucional."

20 Amplias referencias en Antonino SPADARO, Contributo per una teoria della Costituzione, Milán, Giuffrè, 1994, Capt. III ("Verità, etica pubblica e Costituzione").

21 Cit. en Karl POPPER, "Acerca de las llamadas fuentes del conocimiento", en la recopilación de ensayos de dicho autor agrupados bajo el título En búsqueda de un mundo mejor, Barcelona, Paidós, 1994, p. 71. 
La cita que antecede cumple perfectamente, entre los varios posibles, el cometido de ser un cómodo refugio científico, construido además bajo el amparo no de una, sino de dos autoridades (y una de ellas nada menos que presocrática ${ }^{22}$. Con ella se siente uno inducido a concluir este recorrido por ciertos senderos trillados del constitucionalismo. Pero dejaríamos un llamativo cabo suelto si termináramos aquí, sin haber expuesto antes nuestro punto de vista con relación a lo que hemos denominado antes el problema por antonomasia del Derecho Constitucional de nuestros días, es decir, el de cuál sea el método más apropiado para la interpretación de la Constitución.

Alguna vez se ha aplicado a nuestro campo el conocido dicterio "dime lo que piensas de la justicia constitucional y te diré qué concepto de Constitución tienes" ${ }^{23}$; algo que podría también ser enunciado a la inversa o, incluso, ser transformado en "dime tu concepto de Constitución y te diré lo que opinas en materia de métodos interpretativos". Mi particular tela de conjeturas al respecto podría ser expuesta del siguiente modo:

Tengo para mí que a la interpretación de la Constitución le cuadran bien las observaciones de Isaiah Berlin sobre los límites de la teoría en las cuestiones políticas. La desconfianza hacia los intelectuales en el ámbito de la política, dice Berlin, "surge de la creencia, no del todo falsa, de que, debido al deseo de ver la vida de alguna manera simple, simétrica, ponen demasiada esperanza en los resultados beneficiosos derivados de aplicar directamente a la vida conclusiones obtenidas mediante operaciones en una esfera teórica". Y la consecuencia de ello, añade, "es que si los hechos - es decir, el comportamiento de seres humanos vivos - son reacios a tal experimento, el experimentador se molesta, e intenta cambiar los hechos para adecuarse a la teoría, lo que en la práctica significa una especie de vivisección de las sociedades hasta que se conviertan en lo que la teoría originariamente declaraba que el experimento les debería haber convertido" ${ }^{24}$.

Cámbiese «intelectuales" por "constitucionalistas", y "hechos" por "sentencias", y se tendrá una visión certera acerca de las razones de una transposición y, sobre todo, de un escepticismo que hoy comparten muchos autores. Al fin y al cabo, como ya observara Radbruch, la acumulación de investigaciones sobre el método jurídico viene a ser casi siempre indicio de una ciencia carente de salud ${ }^{25}$.

22 Cfr. G. W. BOWERSOCK, "The Art of the Footnote", The American Scholar, 52-53 (1983/84), pp. 54 y ss. y, desde la perspectiva de artículos jurídicos, A. AUSTIN, "Footnotes as Product Differentiation", Vanderbilt Law Review, 40 (1987), pp. 1131 y ss.

23 W. KAEGI, Die Verfassung als rechtliche Grundordnung des Staates, Zürich, 1945, p. 147, cit. en GARCÍA DE ENTERRÍA, La Constitución como norma y el Tribunal Constitucional, Madrid, Cívitas, 1981, p. 163.

24 Isaiah BERLIN, "El juicio político", en El sentido de la realidad. Sobre las ideas y su bistoria, Madrid, Taurus, 1998, pp. 94-95.

25 G. RADBRUCH, Introduzione alla scienza del diritto, Turín, Giappichelli, 1961, p. 360. La cita completa es como sigue: "Las investigaciones relativas al método se acumulan. Del mismo modo que los hombres que se atormentan con la auto-observación son, por lo general, hombres enfermos, así ocurre también con las ciencias que tienen motivos para preocuparse por el método; el hombre sano y la ciencia sana no acostumbran a indagar demasiado sobre sí mismos". 
De ahí que se nos antojen muy acertadas afirmaciones del tipo "el método se hace, no se dice", o bien "del hecho (ex scripto) nace el método (ratio scientia iuris)". Dicho con otras palabras: lo interesante no es la ortodoxia interpretativa abstracta e ideal, sino la concreta (y operativa) orto-praxis constatada. El estudio del método sólo puede ser así un estudio sobre algunas constantes de la praxis ${ }^{26}$.

En esa línea, un trabajo pionero, centrado en el Derecho privado, pero convertido en obra de referencia, descalifica en sus páginas iniciales los empeños teóricos construidos more geometrico: "toda teoría que, renunciando a investigar el fenómeno mismo, hace declaraciones autoritarias e inmediatas sobre su naturaleza y contenido, debe quedar científicamente descalificada, cualesquiera que sean los intereses especulativos que en ello jueguen ${ }^{27}$. La lectura del libro de Esser es muy recomendable para darse cuenta de que el constitucionalismo de nuestros días, al menos por lo que a la interpretación respecta, poca cosa puede descubrir que no sea un "mediterráneo". Especialmente el Capítulo V ("Importancia de los principios constitucionales positivos para la creación jurisprudencial") explica con agudeza los ingredientes de libertad y vinculación que concurren en cualquier aplicación jurisprudencial del Derecho y paradigmáticamente del Derecho Constitucional. Esser toma como ejemplo el principio de igualdad, comparando la posición del juez con la de un observador que, desde la "ventana" de la norma, dirige su mirada hacia los valores sociales admitidos, y hacia el proceso de sedimentación de los mismos «en una conciencia cultural que se apoya en la tradición, pero sujeta a un proceso de renovación constante". De dicha conciencia cultural forma parte la conciencia jurídica, que agrupa, a su vez, la doctrina y el cuerpo de precedentes jurisprudenciales, cuyo decurso evolutivo por la vía de una argumentación sin cortes bruscos ni saltos en el vacío, es la mejor garantía contra cualquier tentación de libre recherche' por parte del juez ${ }^{28}$.

Consideraciones semejantes en torno a la pervasive authority del precedente pueden hallarse también en la obra (más actual que la de Esser) de Orrù, dedicada al derecho jurisprudencial. El autor denuncia las vindicaciones de "retorno al método jurídico" (zurück zur juristischen Methode) como nostálgicas e imposibles de llevar a cabo. Lo que se necesita, según él, es no sustraer al control crítico y a la verificación de la discusión pública, las opciones del juez:

"La legitimidad democrática de las valoraciones realizadas por el juez dependen de la transparencia de sus opciones axiológicas, porque cuando las mismas no son explícitas no pueden ser criticadas ni sometidas siquiera a verificación pública ${ }^{29}$.

26 Cfr. A. SPADARO, "Ex facto (id est: ex scripto) oritur ratio scientiae iuris (Notarella sul metodo 'relazionista' nel diritto costituzionale)", en VV.AA., Il metodo nella scienza del Diritto Costituzionale, Padua, CEDAM, 1997, pp. 157 y ss.

27 Josef ESSER, Principio y norma en la elaboración jurisprudencial del Derecho privado, Barcelona, Bosch, 1961, p. 17.

28 ESSER, Principio y norma..., pp.104-108.

29 Giovanni ORRÙ, Richterrecht. Il problema della libertà e autorità giudiziale nella dottrina tedesca contemporanea, Milán, Giuffrè, 1988, p. 17 y, en general, Cpt. III ("Richterrecht e problematica costituzionale"). 
Si la interpretación supone al propio tiempo un acto de creación jurídica no predeterminado por la norma en todos sus extremos, como afirmaba ya prudentemente la Teoría Pura del Derecho, entonces el acto de voluntad del juez - ordinario o constitucional— tiene que cuajar en una decisión responsable. La resposiveness de la decisión judicial es la que permite paliar el llamado déficit de legitimidad de la jurisdicción en el Estado democrático. En el caso del juez ordinario, porque el eslabón que le une a la soberanía popular mediante la sumisión a la ley es un eslabón quebradizo, como bien lo acredita, con manifiesto realismo, la sujeción adicional del juez a las pautas interpretativas de la justicia constitucional, establecida en nuestra $\mathrm{LOPJ}^{30}$. Y en el caso del juez constitucional, con más motivo, porque al decidir se apodera de la Constitución, por lo menos provisionalmente, en la medida en que a él le corresponde establecer, con carácter vinculante, y sin ulterior recurso, el significado de la misma.

Según una opinión muy difundida, lo que distingue la decisión política de la decisión judicial es precisamente su diferente modo de justificación y argumentación: desde los objetivos que persigue, la primera; desde la sumisión a una norma previa y la exteriorización de la regla utilizada para aplicarla, la segunda ${ }^{31}$. Todo ello es sobradamente conocido. Si lo recordamos, es simplemente para destacar la importancia cobrada en las teorías de la interpretación de nuestros días (lo que es tanto como decir en la actual teoría constitucional) por la racionalidad hermenéutica de la decisión y por la disposición hacia la crítica de los autores de ella.

La gran aporía de las doctrinas postpositivistas de la interpretación constitucional es que cuanto más complejas y detalladas se hacen, llevadas por el deseo de vincular la labor del juez, más ensanchan la discrecionalidad por cuyos márgenes puede moverse cómodamente el intérprete. Bien saben esto los autores de repertorios de principios para la interpretación constitucional, quienes acostumbran a establecer ciertas reservas sobre la utilidad de los mismos. Así ocurre en el trabajo de Hesse sobre la interpretación constitucional, publicado en 1966 como Capítulo II de sus Grunzüge, en el que la admirable precisión con la que es descrita la labor de concreción constitucional, culmina (párrafo n. ${ }^{\circ}$ 76) con unas consideraciones sobre lo aproximativo del empeño:

"Cierto que la decisión jurídica, y muy en particular en el Derecho Constitucional, nunca puede ser racionalizada totalmente; pero ello sólo puede significar que de lo que se trata es de la racionalidad posible, no que sencillamente se pueda prescindir de una metodología consciente. La 'corrección' de los resultados obte-

30 Cfr., in extenso, la reciente recopilación de trabajos de Luis LÓPEZ GUERRA, agrupados bajo el título El Poder Judicial en el Estado Constitucional, Lima, Palestra editores, 2001, y especialmente el Cpt. II ("La legitimidad democrática del juez").

31 Creo que un criterio semejante es el propuesto por Martin KRIELE, aunque mi particular conocimiento del mismo procede de Ignacio DE OTTO, que lo utilizó en bastantes de sus escritos; cfr., por ejemplo, “La sujeción del juez al ordenamiento jurídico”, en Estudios sobre el Poder Judicial, Madrid, Ministerio de Justicia, 1989, pp. 66 y ss. 
nidos a través del proceso expuesto de concretización de las normas constitucionales no tiene, por ello, el carácter de lo exactamente demostrable que puede darse en las ciencias de la Naturaleza; en el ámbito de la interpretación jurídica ello nunca pasaría de ser la ficción y la perpetua mentira de los juristas tras de la cual, y de una forma implícita e incontrolada, se ocultarían los verdaderos motivos de la decisión o esta última sería sencillamente ocultada $»^{32}$.

También Böckenförde, en un Estudio expuesto por vez primera en 1975, y que lleva el significativo título "Los métodos de la interpretación constitucional. Inventario y crítica", finaliza su recorrido con la (decepcionante) conclusión de que «todos los métodos interpretativos producen como resultado, en definitiva (...), la degradación de la normatividad de la Constitución ${ }^{33}$. Una consecuencia, desde luego, indeseable y que procede, según el autor germano, de un error en el punto de mira. Más que depuraciones metodológicas, lo que se precisa es asentar cierto consenso argumentativo, cimentado sobre un concepto de Constitución y una teoría constitucional capaces de "consignar puntos de vista orientadores y estructuras fundadas en ellos para la interpretación". En ese sentido, se pregunta el autor germano si la pretensión indiscriminada de vigencia normativa de todas y cada una de las partes de la Constitución (consecuencia de la atribución a la misma de lo que él llama la función de ley), no debería dejar paso a la idea de ordenamiento marco — una idea, por cierto, a la que nuestro TC se ha mostrado bien adepto_- y a la distinción entre diferentes ámbitos de regulación de la norma constitucional.

Así mismo plantea Böckenförde —y esto es lo que más nos interesa- si no habrá llegado la hora de extraer las consecuencias pertinentes del doble carácter del Tribunal Constitucional, como intérprete cuya labor es mesurable a la luz de la hermenéutica judicial, y como órgano constitucional. Desde este último punto de vista, la determinación de los cometidos de la jurisdicción constitucional hay que buscarla en "la competencia atribuida y en su inserción en el orden de competencias articulante de poderes de la Constitución. (subrayado de E.B.) ${ }^{34}$.

El argumento de Bökenförde es quizá un poco confuso, sobre todo expuesto así en forma mutilada y fragmentaria, pero creo que acierta a resaltar el punto crucial de la cuestión. La mejor garantía de que la interpretación de la Constitución realizada con carácter determinante por el intérprete último no será la burda imposición de la voluntad de unos cuantos jueces con intereses inconfesables, sino el resultado de una operación realizada con arreglo a una técnica jurídica generalmente aceptada, es una de tipo estructural. O, mejor dicho, no una, sino varias razones de tipo estructural.

32 Konrad HESSE, Escritos de Derecho Constitucional, Madrid, Centro de Estudios Constitucionales, 1983, p. 51.

33 E. W. BÖCKENFÖRDE, "Los métodos de la interpretación constitucional. Inventario y crítica", en Escritos sobre derechos fundamentales, Baden-Baden, Nomos Verlagsgesellschaft, 1993, p. 37.

34 "Los métodos de la interpretación constitucional...", pp. 40-42. 
En el orden interno, es decir en el proceso decisorio, la argumentación del juez constitucional sustituye la condición restrictiva de la vinculación a la ley, presente en la argumentación del juez ordinario, por la vinculación a una norma, la Constitución, plagada de disposiciones abstractas, abiertas y con intensa carga ideológica. Pero su argumentación comparte con la del juez ordinario otras condiciones restrictivas, como son la vinculación al precedente y a la dogmática. Especialmente el precedente, como ya lo hemos dicho a propósito de la tesis de Esser, tiene una fuerza general que resulta de dos reglas áureas:

1. Si puede aducirse un precedente en favor o en contra de una decisión, hay que aducirlo.

2. Quien quiera apartase de un precedente, corre con la carga de la argumentación ${ }^{35}$.

El voto particular del magistrado Rodríguez Bereijo en la STC 222/92 (Caso subrogación arrendaticia mortis causa en uniones de becho), un voto del que se ha dicho que es «una de la páginas de Derecho Constitucional más lúcidas que se han escrito en este país durante los últimos años ${ }^{36}$, se centra precisamente en la supuesta vulneración de la segunda de dichas reglas por parte de la mayoría del Tribunal:

"No se trata, claro está, de 'sacralizar' el respeto a la jurisprudencia constitucional, de modo que resulte imposible su cambio o modificación. Ello conduciría a una petrificación, a todas luces indeseable, de nuestra interpretación constitucional. Es, pues, no sólo legítima, sino también saludable, una evolución progresiva en la interpretación constitucional. Pero ello debe hacerse, además de con la necesaria prudencia y equilibrio, siempre de manera explícita y razonada, (...) para no generar incertidumbre e inseguridad jurídica respecto del sentido y alcance de la interpretación constitucional que a este Tribunal compete. Si los cambios u oscilaciones bruscos en toda jurisprudencia son siempre peligrosos, lo son mucho más cuando de la jurisprudencia constitucional se trata".

Se dirá que el consenso argumentativo, reclamado por Böckenförde en su artículo sobre los métodos de interpretación, fue vulnerado en el caso recién aducido. Pero ahí está el voto particular para establecer la crítica, y ahí está la doctrina, libre de las restricciones consustanciales a la decisión judicial, para airear la denuncia y reclamar contención. La justicia constitucional es siempre justicia que se administra de forma colegiada y siguiendo reglas estrictas de formación de voluntad, que pueden ser, por sí solas, una garantía de «elección

35 Robert ALEXY, Theorie der juristischen Argumentation, p. 339, en auto-cita del propio Alexy, Teoría de los derechos fundamentales, Madrid, Centro de Estudios Constitucionales, 1993, p. 537. También Sunstein insiste en la misma idea: “(...) Much of the discipline on judges comes not from constitutional text and history, but from past cases ...", Legal Reasoning and Political Conflict, cit., pp.180 y ss.

36 Ángel GARRORENA, en la «Encuesta sobre la orientación actual del Derecho Constitucional,, Teoria y Realidad Constitucional, 1 (1998), p. 43. 
racional". A falta de trabajos que profundicen en ese aspecto de la cuestión, al estilo norteamericano ${ }^{37}$, lo que sí es seguro es que no hay decisión de la justicia constitucional que no sea "mirada con lupa" por los teóricos y por los demás operadores jurídicos.

El conjunto de reglas, institucionalizadas o no, en materia de argumentación, actuantes en el proceso de aplicación del Derecho, forma parte, según Alexy, de un modelo de sistema jurídico articulado en tres niveles: uno, el de las reglas; un segundo, el de los principios; y un tercero, el del procedimiento:

"Lo que hasta ahora se ha descrito, el nivel de la regla y el de los principios, no proporciona un cuadro completo del sistema jurídico. Ni los principios ni las reglas regulan por sí mismos su aplicación. Ellos representan sólo el costado pasivo del sistema jurídico. Si se quiere obtener un modelo completo, hay que agregar al costado pasivo uno activo, referido al procedimiento de la aplicación de las reglas y de los principios (...). En un sistema orientado por el concepto de la razón práctica, este tercer nivel puede ser sólo el de un procedimiento que asegure la racionalidad, ${ }^{38}$.

De la misma forma que su Teoría de los derechos fundamentales nos recuerda que la Constitución no contiene sólo principios de índole material, sino también principios "procedimentales" (por ejemplo, entre otros muchos, el que dispone que es al legislador democrático a quien corresponde adoptar las decisiones más importantes para la comunidad) ${ }^{39}$, Alexy entiende aquí que un sistema jurídico atrapado por la disyuntiva "modelo de reglas" versus "modelo de principios" (¿legalismo versus constitucionalismo?), sólo puede salir de semejante trampa mortal, supliendo las carencias de uno y otro modelo mediante la contribución del "tercer nivel" del sistema jurídico, el de la racionalidad práctica procedimental:

"Hay que excluir un legalismo estrictamente orientado por las reglas. Por razones de racionalidad práctica, es irrenunciable la presencia de principios y con ello - dicho con otra terminología - de valores en el sistema jurídico. En un Estado constitucional democrático, los principios tienen si no exclusivamente sí en buena parte su ubicación jurídico-positiva en la Constitución. No se pierde por ello la

37 Vienen de inmediato a la cabeza al menos dos obras, la clásica de WOODWARD y ARMSTRONG, The Brethren, Nueva York, Simon \& Schuster, 1979, que cubre el período 1969-1976, y la más reciente, de David Savage, Turning Right. The Making of the Rehnquist Supreme Court, Nueva York, John Wiley \& Sons, 1992; por no hablar de la serie de obras publicadas a raíz de la decisión del Tribunal Supremo en el asunto del recuento de los votos de Florida durante las elecciones presidenciales de 2000, por ejemplo la de Alan DERSHOWITZ, Supreme Injustice, Nueva York, Oxford University Press, 2001, o la editada por C. SUNSTEIN y R. EPSTEIN, The Vote: Bush, Gore and the Supreme Court, Chicago, University of Chicago Press, 2001. En 2001 vio además la luz la monumental The Supreme Court in Conference (1940-1985): the Private Discussions behind nearly 300 Supreme Court Decissions, Nueva York, Oxford University Press.

38 ALEXY, "Sistema jurídico y razón práctica", en El concepto y la validez del Derecho, Barcelona, Gedisa, 1994, p.173.

39 Teoría de los derechos fundamentales, cit., p. 133. 
independencia del derecho legislado ordinario. En el modelo de tres niveles se convierte en un problema de la ponderación entre el principio formal de la competencia de decisión del legislador legitimado democráticamente y los principios materiales de la Constitución. Los resultados de esta ponderación, al igual que de otras ponderaciones, son fundamentables racionalmente, ${ }^{40}$.

Sobre la base de tales afirmaciones, no creo que sea exagerado decir que si el núcleo de la teoría constitucional de nuestros días es la interpretación de la Constitución, el núcleo de la interpretación de la Constitución no es otro que el del deslinde de atribuciones respectivas, en el desempeño de tal cometido, entre el legislador democrático y el juez constitucional.

Pero con ello volvemos al punto del que partíamos a propósito de las observaciones de Habermas contra la invasión de la justicia constitucional. Permítasenos añadir ahora un par de consideraciones a modo de epílogo.

Una tradición jacobina y varias décadas de positivismo legalista dificultan en Europa algo que en los Estados Unidos se contempla con toda naturalidad. Me refiero a las resistencias que aquí levanta todavía la idea de que el juez, cualquier juez, desempeña una función política; tanto más si su cometido es interpretar la Constitución, en el seno de un Tribunal cualificado como supremo intérprete de ella y que, en su condición de órgano constitucional, forma parte (como dirían los norteamericanos) de una society's governing coalition. Entre los miembros de dicha coalición gobernante, por otro nombre "poderes del Estado", resulta consustancial a la lógica del Estado Constitucional que se produzca cierta tensión. Al fin y al cabo, si hay dos conceptos claves en el funcionamiento de tal tipo de Estado, uno de ellos es el de derechos fundamentales, pero el otro, como bien ha resaltado Aragón Reyes, es el de control, y un control deja de serlo genuinamente cuando el controlador (o quien actúa como tal, pues las funciones pueden ser intercambiables) hace de la condescendencia su guía de conducta. Otra cosa es que dicha tensión desemboque en un conflicto irresoluble y susceptible de causar, por su persistencia, un bloqueo institucional. Pero de ello la historia, al menos en un contexto democrático, ofrece contadísimos ejemplos ${ }^{41}$.

A partir de un argumento tan cargado de naïveté, quizá resulte más sencillo admitir que el legislador y el Tribunal Constitucional comparten un mismo "ámbito de diálogo", en el seno del cual cada uno conserva una capacidad de reacción que excluye monopolios de la última palabra. La labor de la justicia constitucional al enjuiciar el producto de la voluntad del legislador se parece así

40 ALEXY, "Sistema jurídico y razón práctica», pp. 176-177.

41 Remito al clásico trabajo de Robert DAHL, "Decision-Making in a Democracy: the Supreme Court as a National Policy-Maker", The Journal of Public Law, 6 (1957), pp.279 y ss., donde se demuestra la sintonía esencial, comprobable a la larga, entre los puntos de vista del Congreso y los del Tribunal Supremo. Cuando hago la salvedad del contexto democrático, estoy pensando en el caso del Perú, donde hace algunos años, el conflicto entre el presidente Fujimori y el Tribunal Constitucional, a propósito del cómputo de los mandatos presidenciales a efectos de reelección, se resolvió, de la manera más grotesca, con la destitución de varios magistrados. 
cada vez más a un "diálogo no coercitivo" que a menudo sugiere, más que impone, unos caminos en vez de otros, en aras de la supremacía de la Constitución ${ }^{42}$. "Nadie como el poder judicial —escribe Laurence Tribe, expresando la misma idea - se halla capacitado para, y tiene el compromiso de, desarrollar un discurso constitucional capaz de justificar y aportar razones que sustenten su opinión sobre el comportamiento de los otros poderes, mediante un diálogo con quienes leen la misma Constitución, aun cuando el punto de vista de unos y de otros pueda ser distinto" ${ }^{43}$.

Quien conceda crédito (por decirlo con Bickel) a las "virtudes pasivas" de la justicia constitucional, no verá, en definitiva, que el manido rasgo contramayoritario de ella plantee "dificultad" alguna ${ }^{44}$; y como consecuencia de ello, la afanosa búsqueda del único método interpretativo respetuoso con las esencias democráticas, fuente de tantas polémicas, pierde buena parte de sentido,

Por más que dicha postura pueda ser tildada de abandonista, parece estar abriéndose paso la idea de que el Derecho Constitucional se ha troceado en zonas normativas que exigen un tratamiento diferenciado; o, lo que viene a ser lo mismo, está emergiendo la convicción de que las grandes teorías omnicomprensivas sobre interpretación de la Constitución (teorías prescriptivas de una ortodoxia que a menudo tienen mucho de pie forzado) son incapaces de dar cuenta de una realidad constitucional poliédrica, en la que los hechos -léase las decisiones de los intérpretes- "hablan por sí solos" "45.

Analizando un fenómeno de esa naturaleza, Mark Tushnet defiende la opinión de que las "grandes teorías" interpretativas de la doctrina norteamericana tan sólo sirven si uno acepta no sobrepasar los confines propuestos, a modo de petición de principio, por cada una de ellas. Además, el mismo autor constata que lo que vale para cuestiones de libertad de expresión - digamos las teorías de Ely sobre apertura de los canales de participación y refuerzo de la representación - generalmente resulta inútil en otras "áreas", por ejemplo, en materia de privacidad, discriminación por razón de sexo o justicia penal, donde se exigen buenas dosis de filosofía moral, al estilo Dworkin, o de origina-

42 Tal es el argumento, a veces un poco forzado, que desarrolla Robert Burt en su trabajo "Constitutional Law and the Teaching of Parables", Yale Law Journal, 93 (1984), pp. 455 y ss. Burt toma como paradigma el diálogo entre el Tribunal Supremo, el Congreso y la opinión pública a que dio lugar la decisión del caso Brown v. Board of Education. En la misma idea del diálogo entre el Tribunal y el Congreso insisten diferentes trabajos de Ferejohn y Weingast, una reseña de los cuales, a cargo de Pablo Salvador Coderch, puede verse en el Anuario de Derecho Civil, XLV (1992), pp. 1591 y ss.

43 Laurence TRIBE, American Constitutional Law, Mineola, The Foundation Press, 1988, p.15, y del mismo autor, junto con M. DORF, in extenso, On Reading the Constitution, Cambridge, Harvard University Press, 1991, pp. 32 y ss.

44 Alexander BICKEL, The Least Dangerous Branch. The Supreme Court at the Bar of Politics, New Haven, Yale University Press, 1986, Cpt. IV.

45 Cfr. la intervención de Cesare PINELLI, recogida en el libro Il metodo nella Scienza del Diritto Costituzionale, cit., pp. 110 a 113. El autor recurre a la imagen de un glaciar que se disuelve en ríos distintos para ilustrar la fragmentación metodológica experimentada por el Derecho Constitucional. 
lismo, constatación que también vale a la inversa ${ }^{46}$. La conclusión del libro de Tushnet, tras más de 300 páginas de análisis minucioso, no puede ser más desalentadora:

"La tradición liberal hace de la teoría constitucional algo al mismo tiempo necesario e imposible. Necesario porque aporta el tipo de limitaciones que tal tradición prescribe para quienes mandan, ya sean legisladores o jueces. Pero imposible, porque no hay teoría constitucional capaz de satisfacer simultáneamente el doble objetivo de marcar límites a la actividad del legislador y a la del juez. Cuanto más limitaciones propugnemos para los jueces, más libre de ellas dejaremos al legislador; y cuanto más limitemos al legislador, más libertad dejaremos a los jueces para hacer lo que ellos quieran" ${ }^{47}$.

Menos mal que la teoría constitucional siempre podrá extraer de la chistera el socorrido recurso de la autocontención judicial, algo que no justifica, desde luego, las alforjas empleadas para el viaje.

La judicial self-restraint viene a ser el equivalente doctrinal de la candorosa estipulación constitucional que prescribía el ser justos y benéficos. Aunque su linaje no es tan antiguo como el de dicha estipulación, tampoco es desdeñable; procede, al parecer, del voto particular firmado en 1936 por el juez Stone en Butler $v$. United States, un caso hoy célebre por haber sido el detonante de la "guerra" entre el Tribunal y el presidente Roosevelt, a propósito del New Deal. Disconforme con la declaración de inconstitucionalidad de la Agricultural Adjustment Act, el juez Stone dejó escrito, en frase que ha hecho fortuna, que "the only check upon our exercise of power is our own sense of self-restraint, ${ }^{48}$. En 1924, un trabajo dedicado a la Judicial Self-Limitation sostenía ya que los jueces deberían abstenerse de dar opinión en los asuntos políticos particularmente espinosos (prickly issues) o candentes (politically hot), así como en aquellos que afectaran al hipersensitive nerve of public opinion ${ }^{49}$.

Se trata, como se ve, de formulaciones prescriptivas que poco añaden a lo que ya se infiere del principio estructural de la división de poderes, en lo que tiene de reserva en exclusiva de un núcleo intocable de funciones para cada uno de ellos. Si de prescribir se trata, no se ve la causa por la que la virtud de la contención y el fair play no deba preconizarse también con respecto a los titulares de los órganos político-representativos. Por ejemplo para evitar que, como ha sucedido entre nosotros varias veces, la dinámica del Estado de partidos produzca el efecto de bloquear contra legem, y más allá de todo plazo razonable, la renovación del Tribunal Constitucional.

46 Mark TUSHNET, Red, White and Blue. A Critical Analysis of Constitutional Law, Cambridge, Harvard University Press, 1988, Cpt V ("Intuitionism and Little Theory").

47 Red, White and Blue..., p. 313.

48 Butler v. U.S., 297 U.S., 1, 34; para el contexto del caso, cfr. Laurence TRIBE, God Save this Honorable Court. How the Choices of Supreme Court Justices Shapes our History, Nueva York, Penguin, 1986, pp. 80-82.

49 M. FINKELSTEIN, "Judicial Self-Limitation", Harvard Law Review, 338 (1924), pp. 344 y ss. 
Como escribió Cappelletti en su clásico trabajo sobre los jueces-legisladores, el buen juez no es el juez contenido, sino aquel que, consciente de la grandeza y de las debilidades de la función que desempeña, es capaz de discernir si las circunstancias del caso aconsejan ser cauteloso o audaz, desplegando, en consecuencia, de manera convincente, los argumentos jurídicos que procedan ${ }^{50}$.

Bien sé que anular disposiciones de una ley —no una ley, como se suele decir siempre, y muy raras veces, que yo sepa, ocurre - no es cuestión baladí. También soy consciente de que el carácter de la Constitución como norma-marco conlleva exigencias muy concretas dirigidas a salvaguardar el producto de la voluntas legislatoris. Por lo demás, nadie como el ex-presidente del Tribunal, Tomás y Valiente, supo defender con tanto énfasis, en decisiones por él firmadas como juez constitucional, y en exposiciones públicas, el valor de la autocontención ${ }^{51}$. Pero lo que no logra convencerme es el intento de elevar la selfrestraint de la jurisdicción constitucional a la condición de principio o criterio marco para la interpretación constitucional.

Dicho intento está en el trasfondo de muchas elaboraciones doctrinales sobre el "lugar" del juez constitucional; aparece, por ejemplo, en un trabajo de Antonio Troncoso, titulado «Método jurídico, interpretación constitucional y principio democrático", cuya tesis básica es que la eficacia jurídica del principio democrático exige autocontención judicial en la interpretación de las cláusulas generales cuando de los procedimientos de control de constitucionalidad se trata. La deferencia con el legislador debería ser así la suprema lex del juez constitucional, a menos que se encontrara ante un supuesto de incompatibilidad manifiesta entre la Constitución y el texto enjuiciado, o bien cuando el parámetro de juicio no fuera una cláusula general, sino una cláusula cerrada o, con otros términos, una regla constitucional ${ }^{52}$.

Dejando de lado la dificultad que entraña distinguir entre cláusulas abiertas y cerradas, y al margen de que es poco probable que se dé una contradicción manifiesta entre Constitución y ley, el problema es, una vez más, el del punto de partida. Lo que explica el resurgimiento y la generalización en nuestros días de la (llamada) "jurisdicción de la libertad" no es el "miedo al principio democrático", sino precisamente la desconfianza en el legislador y el imperativo de la defensa de los derechos.

Desde tal presupuesto se comprenden mejor las cautelas de la propia Constitución en materia de garantía de los derechos, cautelas que lo son fren-

50 Mauro CAPPELLETTI, Giudici legislatori?, Milán, Giuffrè, 1984, p.82

51 Ejemplo de lo primero puede ser su voto particular a la STC 53/1985 (caso despenalización del aborto), y de lo segundo muchos de sus artículos y conferencias; como muestra puede verse el titulado "Juzgar, arbitrar, legislar", recogido en A orillas del Estado, Madrid, Taurus, 1996, pp. 25 y ss., donde Tomás y Valiente deja constancia de que la autorrestricción "ha sido y es preocupación constante (del Tribunal), posibles errores al margen".

52 Antonio TRONCOSO, "Método jurídico, interpretación constitucional y principio democrático", recogido ahora en Eduardo ESPÍN y Francisco J. DÍAZ REBORIO (eds.), La Justicia Constitucional en el Estado Democrático, Valencia, Tirant lo Blanch, 2000, pp. 399 y ss. 
te al legislador: exigencia de mayoría cualificada en la reserva de ley orgánica y garantía del contenido esencial de los derechos. No hay un "núcleo menor" de contenido esencial frente al legislador y otro más exigente frente a la actividad de la Administración o la de los jueces ordinarios. El contenido esencial es uno, y es uno frente al legislador, quien encuentra precisamente ahí el límite infranqueable al contenido legal por él estatuido. Y a quien corresponde razonar si tal límite ha sido o no respetado, es al Tribunal Constitucional.

En último extremo se trata no de una cuestión de conceptos, sino de concepciones. La cualidad, y la calidad, democrática no es hoy mensurable según el simple criterio del "respeto a la voluntad de la mayoría", sino con arreglo a los cánones "respeto de las minorías" y, sobre todo, "garantías de los derechos". Entre otras cosas, porque lo primero es retórica huera si falta lo segundo. La voluntad de la mayoría se forma sobre la base de la celebración periódica, y con las debidas garantías, de elecciones libres y competitivas. De ellas surge un legislador plural, tanto más plural cuanto más genuinamente política sea la división territorial del poder. La idea de una voluntad univoca del legislador contrapuesta a la de unos jueces que nadie ha elegido resulta, en definitiva, tan burda y simplista como la del legislador proclive a vulnerar los derechos, vigilado y contenido por los guardianes de la Constitución.

$\mathrm{Si}$, como la historia enseña, el constitucionalismo y la democracia han tendido a presentarse en relación conflictiva, los componentes de uno y de otro confluyen hoy en un mismo ámbito conceptual cada vez más riguroso y exigente. De cara al futuro, la universalización de lo que el constitucionalismo implica, y la generalización y profundización de lo que la democracia demanda, deberían ser, en tanto que ideales por todos compartidos, la suprema guía de conducta. 